\title{
PERSPECTIVAS DE FUTURO DOS JOVENS ESTUDANTES DO ASSENTAMENTO SÃO JOSÉ: FRENTE AO FENÔMENO DE ENVELHECIMENTO DA POPULAÇÃO RURAL
}

\author{
FUTURE PERSPECTIVES OF THE YOUNG STUDENTS OF THE JOSÉ ASSENTAMETTE: \\ AGAINST THE RURAL POPULATION AGING PHENOMENON
}

\author{
Alessandra Caroline Ghiorzi \\ Mestre em Antropologia Social pela Universidade Federal de Santa Catarina (UFSC) \\ E-mail: alessandra@ghiorzi.com.br
}

Eleandra Negri Costa

Especialista em educação a Distância Pela (POSEAD) Professora na Escola Estadual Vila Rica (EEVR).

\author{
Maria do Rosário Soares Lima \\ Mestre em História pela Universidade Federal de Mato Grosso (UFMT) \\ E-mail: mariadorosariovilarica@gmail.com
}

Rosaline Araújo de Morais Piastrelli Especialista em tecnologias digitais e inovação na educação pela Universidade Candido Mendes (UCAM). Professora na Escola Estadual Vila Rica (EEVR).

E-mail: rosalinearaujo16@gmail.com

\begin{abstract}
Resumo: A crescente saída de jovens da zona rural tem sido uma preocupação recorrente da sociedade brasileira, sobretudo por causa do envelhecimento da população rural. Esse estudo teve como objetivo identificar as perspectivas de futuro dos jovens estudantes moradores do assentamento São José localizado no município de Vila Rica-MT analisando as variáveis que influenciam nas decisões e quais as motivações dos jovens em permanecer ou sair do campo. $\mathrm{O}$ presente estudo foi de abordagem quantitativa e qualitativa e para a coleta de dados usou-se de questionários. Esse estudo traz um alerta para as profundas transformações na comunidade rural, visto que a comunidade em estudo se caracteriza pelo desenvolvimento de uma agricultura familiar e o futuro dessas unidades produtivas depende do interesse dos jovens que são os futuros sucessores em permanecer ali. O que se apresenta é a falta de meios para incentivar, e gerar oportunidades do jovem se manter no campo.
\end{abstract}

Palavras-chave: Juventude; Agricultura Familiar; Campo.

Abstract: The growing outflow of young people from rural areas has been a recurrent concern of Brazilian society, especially because of the aging of the rural population. This study aimed to identify the future perspectives of the young students living in the São José settlement located in the municipality of Vila Rica-MT, analyzing the variables that influence the decisions and the motivations of young people to stay or leave the field. The present study was of quantitative and qualitative approach and the data collection was done using questionnaires. This study brings an alert to the deep transformations in the rural community, since the community under study is characterized by the development of a family agriculture and the future of these productive units depends on the interest of the young people who are the future successors to 
remain there. What is presented is the lack of means to encourage, and generate opportunities for the young to remain in the field.

Keywords: Youth; Family farming; Field.

\section{Introdução}

A crescente saída de jovens da zona rural tem sido uma preocupação recorrente da sociedade brasileira, uma vez que esse cenário direciona os rumos da concentração da população urbana. Essa inquietação pode ser explicada a partir de diferentes fatores, dentre outros, destaca-se a falta de perspectiva de políticas públicas direcionadas a juventude que vive nos assentamentos rurais. Esse fenômeno tem mudado a dinâmica do campo e tem implicado em muitas consequências, sobretudo o envelhecimento da população rural.

Levando em consideração a relevância dos jovens enquanto uma categoria social fundamental para a continuação da população rural, alunos do ensino médio de uma sala anexa da Escola Estadual Vila Rica que é anexada na Escola Municipal Nazaré ${ }^{1}$, localizada no assentamento São José da zona rural do município de Vila Rica-MT, escolheram a partir do "Projeto Lugar Onde Eu Vivo"”, identificar as perspectivas de futuro dos jovens estudantes moradores do assentamento em questão. Para tanto, procurou-se analisar as variáveis que influenciam nas decisões equais as motivações dos jovens em permanecer ou sair do campo, e também observar a influência da família quanto às escolhas dos jovens daquela localidade.

Os 22 (vinte e dois) alunos envolvidos na pesquisa possuem faixa etária entre 13 a 21 anos, compostos por nove alunos do $9^{\circ}$ ano do ensino fundamental e treze do ensino médio, sendo que 52\% desses jovens são do sexo masculino. Todos os alunos são residentes no assentamento São José, cuja maioria das propriedades desse assentamento trata-se de áreas tuteladas, ou seja, pertencentes ao Instituto Nacional de Colonização e Reforma Agrária (INCRA).

O projeto de assentamento São José foi criado em decorrência de um processo de reocupação da Fazenda de igual nome: São José, localizada na zona rural do município de Vila Rica-MT que foi reocupada pelos trabalhadores rurais, os quais na época alegavam que a

\footnotetext{
${ }^{1}$ A Escola Municipal Nazaré é organizada via a modalidade da educação do Campo, voltada para alunos que residem no meio rural, sendo algumas anexadas à escola localizada na área urbana. A Escola Municipal Nazaré compõe a modalidade de escola do campo e é vinculada à Escola Estadual Vila Rica.

${ }^{2}$ O "Projeto Lugar Onde Eu Vivo" é realizado anualmente desde $2017 \mathrm{em}$ todas as escolas do campo anexadas à Escola Estadual Vila Rica. Trata-se de um projeto de ensino e pesquisa.
} 
fazenda se encontrava em condições de improdutividade e devedora para o Banco do Brasil, situação essa que na opinião dos "posseiros" 3 facilitariam a negociação de pertencimento, entre o Instituto Nacional de Colonização e Reforma Agrária (INCRA) e o proprietário da fazenda. Ainda em relação à história do assentamento é importante destacar que os agricultores familiares datam o início da reocupação em 1995, no entanto, constam-se nos dados do INCRA que o processo de regulamentação ocorreu somente em $1998^{4}$ (LIMA, 2016).

O presente estudo foi de abordagem quantitativa e qualitativa com o uso de questionário fechado para os alunos, enquanto para os pais aplicou-se questionário com questões tanto abertas quanto fechadas para coleta dos dados. Tendo em vista que esseartigo é resultado das ações realizadas pelo "Projeto Lugar Onde Eu Vivo" que se trata de um projeto de ensino e pesquisa, consideramos ser importante destacar que ao longo do desenvolvimento do referido projeto, buscou-se desenvolver com os alunos a metodologia de elaboração de projetos.

Para isso, foram realizadas oficinas de orientação sobre normas e técnicas de pesquisa e de estruturação de projetos, bem como organização de grupos de estudos para definição de referencial teórico, construção e aplicação de questionários. Posterior fez-se oficinas de tabulação de dados e análise dos resultados em forma de construção de gráficos.

\section{Referencial teórico}

O processo de modernização que a sociedade atual tem vivido tem incitadomudanças significativas no meio rural, não somente no que diz respeito ao aumento da produtividade com a inovação de maquinários nas modernas formas de manejo e outras tecnologias, e também nas transformações causadas a população que reside nesse meio. Essas mudanças impactam o modo de vida na agricultura familiar, o empobrecimento da população, o envelhecimento e a não

\footnotetext{
${ }^{3}$ Termo utilizado para nomear a categoria de agente social ocupante de áreas de fazendas improdutivas, conforme Puhl (2003) apud Lima (2016 p. 67) “[...] ocupação antiga de áreas devolutas ou sem documentação privada; o uso direto da terra no trabalho de produção agropecuária; a residência e o trabalho da família na posse, a resistência à retirada ou expulsão levada a efeito por grileiro".

${ }^{4}$ Referência sobre o assentamento São José ver em: LIMA, Maria do Rosário Soares. A Transformação de Posseiros em Agricultores Familiares: História e Memoria da Reocupação de Vila Rica-MT. Dissertação (mestrado)-Universidade Estadual de Mato Grosso, Instituto de Ciências Humanas e Sociais, Programa de PósGraduação em História, Cuiabá, 2016.
} 
permanência de jovens no campo, conforme podemos observar nas palavras de Godoy et al. (2010).

[...] com a modernização no campo houve um agravamento das condições de vida dos agricultores familiares, ou seja, o empobrecimento e endividamento de grande parte dos agricultores e, também o deslocamento significativo da população rural para os centros urbanos. Os agricultores que permaneceram no campo lutam para conseguir produzir e manter a qualidade de vida da sua família e o seu bem-estar. (GODOY et al. 2010, p. 2),

Quando referimos ao termo juventude, estamos falando de uma fase da vida de descobrimento e experimentação, já que tanto os processos de construção da identidade, como a construção dos projetos de vida estão em etapa de formação. Se falarmos de perspectivas de futuro, é importante levar em conta as características e os anseios individuais, relacionando-os com o meio que o cerca. Ao falarmos da juventude rural, a preocupação com a temática é gerada principalmente pelos preocupantes índices de esvaziamento do meio rural por parte dos jovens, grupo que é responsável pela continuidade da população no meio rural. Puntel, Paiva e Ramos, (2011) elucidam isso ao expor que:

\begin{abstract}
Além do aumento da expectativa de vida nas últimas décadas, outro fator que contribui para o envelhecimento da população do campo é o êxodo dos jovens rurais para o meio urbano. Acreditamos que este movimento é revelador da situação e percepção dos jovens sobre a realidade em que vivem e indicador de que estamos vivendo um acelerado período de transformação no qual a incerteza parece predominar. (PUNTEL; PAIVA; RAMOS, 2011, p. 2).
\end{abstract}

Os autores fazem menção no que diz respeito à desvalorização do meio rural por parte dos jovens, que tem cooperado para a saída deles para as cidades com o intuito de buscarem novas formas de se viver. É interessante destacar que essa desvalorização não é algo proveniente dos jovens em si, mas sim, um pouco do que carregam de "uma tendência tão própria da nossa sociedade de desvalorização do meio rural" (ABRAMOVAY, 1998, p. 143), que encaram o campo como um lugar de pessoas que ainda não marcharam em direção à “civilização", como bem escreveu Abramovay (1998).

Ao tratarmos de agricultura familiar em seu conceito tradicional podemos defini-la como um segmento econômico e social em que são trabalhadas atividades agropecuárias e agrícolas desenvolvidas no meio rural gerenciada por mão de obra predominante familiar (Schneider, 2003). Isso não quer dizer que esse tipo de agricultura não possa fazer parte de um plano extensionista economicamente viável, conforme afirma Abramovay (1998, p. 145): 
“existe uma clara consciência de que não só ela tem um peso social majoritário, mas também que ela poderia preencher uma função decisiva na própria oferta agropecuária”, como mais adiante o autor aponta que há um "grande potencial econômico" da agricultura familiar (Abramovay, 1998, p. 145).

Podemos destacar como contribuições importantes da agricultura familiar a responsabilidade de compor mais de $70 \%$ dos alimentos que chegam à mesa dos brasileiros e responde por $38 \%$ do valor bruto da produção agropecuária, além de conseguir empregar três vezes mais do que a agricultura não familiar (Banco da Amazônia, 2018).

Segundo Breitenbach e Corazza (2017), os principais ensejos para a emigração dos jovens para as cidades são os atrativos que a vida urbana propõe, muitos jovens buscam principalmente alternativas econômicas e educativas diferentes daquelas encontradas no meio rural. Como vimos anteriormente, a agricultura familiar possui alternativas econômicas viáveis (ABRAMOVAY, 1998), entretanto quando comparamos a questão de incentivo por parte do governo, a agricultura mecanizada de grande escala recebe muito mais fomento do que a agricultura familiar, por isso, esta não consegue desenvolver todo o seu potencial econômico.

Podemos observar isso desde o início da ocupação da Microrregião Norte Araguaia ${ }^{5}$ quando, na década de 1960, grandes empresários oriundos principalmente de São Paulo vieram para a região atraídos pelos incentivos fiscais fornecidos pela Superintendência do Desenvolvimento da Amazônia (SUDAM), ganhando ou comprando terras do governo. Entretanto, outros incentivos foram ofertados pela SUDAM, como por exemplo: a isenção de impostos de renda, de taxas federais, tributos para importação de máquinas e equipamentos, bem como com créditos facilitados para atividades industriais, agrícolas e pecuárias. (BARROZO, 2007). Além disso, em 1996 foi aprovada a lei Kandir que isenta os produtores de soja do Imposto sobre Circulação de Mercadorias e Serviços (ICMS), como descrevem Barrozo e Rosa (2017).

Apesar de existirem incentivos do governo para a agricultura familiar, como o Programa Nacional de Fortalecimento da Agricultura Familiar (PRONAF) e Assistência Técnica e Extensão Rural (ATER), esses programas não alcançam toda a população rural brasileira, principalmente no caso da maioria dos assentamentos da Microrregião Norte

\footnotetext{
${ }_{5}^{5}$ A microrregião é composta pelos municípios: Ribeirão Cascalheira, Porto Alegre do Norte, Canabrava-do-Norte, Confresa, Vila Rica, Serra Nova Dourada, Novo Santo Antônio, Santa Terezinha, São Félix do Araguaia, São José do Xingu, Luciara, Alto Boa Vista, Bom Jesus do Araguaia e Santa Cruz do Xingu, conforme IBGECidades.
} 
Araguaia, contribuindo para a falta de infraestrutura como o uso de técnicas modernas e a facilidade na obtenção do crédito, já que por não possuírem o título da terra não podem utilizar de outros modelos de empréstimos para o desenvolvimento de sua propriedade. Além disso, na maioria dos assentamentos rurais desta parte do estado de Mato Grosso, há pouco investimento público para construção de estradas, saneamento, hospitais e escolas. Esta última é apontada por Breitenbach e Corazza (2017) como um dos motivos alegados pelos jovens para a saídado campo.

Com isso, a continuação do jovem no campo pode ser estimulada por ações que pautem em um processo de melhoria das condições de vida e valorização da população rural. É muito importante que o poder público amplie e defina mais políticas públicas e incentivos financeiros à agricultura familiar, de maneira que desperte o interesse do jovem em permanecer no campo e que possa ser valorizado pelo seu trabalho rural. (GODOY et. al, 2010). O futuro dos estabelecimentos rurais familiares depende do interesse dos jovens, consequentes sucessores, em permanecer na unidade produtiva (CARNEIRO, 2001). A saída dos jovens para a cidade se mostra como um impasse para a continuação do desenvolvimento da agricultura familiar e da economia do Brasil.

\section{Metodologia e resultados}

Os dados obtidos nesse estudo tiveram como metodologia a aplicação de questionários para os jovens estudantes da escola localizada no assentamento São José-MT e para os pais ${ }^{6}$ desses jovens. Quanto aos sujeitos da pesquisa envolveram-se 22 (vinte e dois) alunos com faixa etária entre 13 a 21 anos, e 13(treze) pais.

O questionário elaborado para a aplicação da pesquisa foi composto de nove questões fechadas para os alunos, e outro questionário de nove questões abertas e fechadas aplicadas para os pais dos alunos. O teor das questões aplicadas aos alunos gira em torno de: Onde pretende realizar o projeto de vida; incentivo da família para continuar no campo; principais problemas na vida do campo.

No questionário direcionado aos pais buscou-se obter a visão deles quanto aos mesmos questionamentos feito aos alunos, tais como: se a realidade rural vivida hoje contribui para

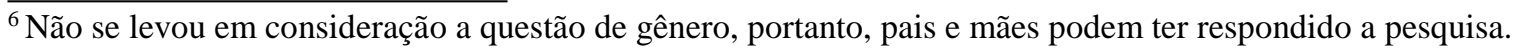


manter os jovens vivendo no meio rural; onde pretendem que o seu filho realize seu projeto de vida.

O gráfico 1 demonstra a classificação quanto ao gênero dos jovens alunos pesquisados, a maioria é do sexo masculino, sendo $52 \%$ da população pesquisada e $48 \%$ são do sexo feminino.

\section{Gráfico 1: Gênero sexual dos alunos pesquisados}

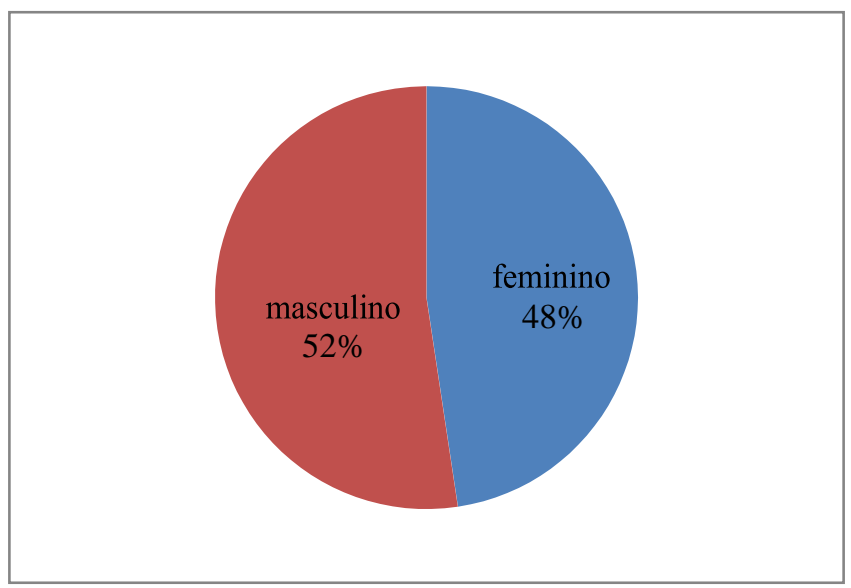

Fonte: Resultado, elaboração própria/2018.

Analisando o tempo que as famílias dos jovens pesquisados residem no meio rural, $62 \%$ moram de 15 a 25 anos nesse ambiente, $23 \%$ de 25 a 45 anos e $15 \%$ de 1 a 15 anos. Essa informação mostra que a maioria das famílias que residem no assentamento tem um vínculo histórico com o campo.

Diante do exposto é possível afirmar que a grande maioria dos alunos do $9^{\circ}$ ano do ensino fundamental da Escola municipal Nazaré e os alunos do ensino médio da sala anexa da Escola Estadual Vila Rica nasceram no ambiente rural.

Gráfico 2: Tempo que residem no meio rural

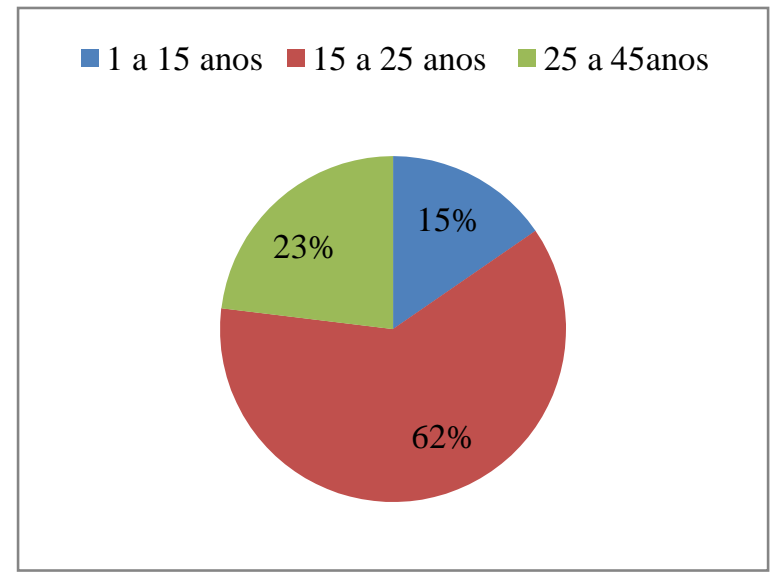

Fonte: Resultado, elaboração própria/2018. 
Quando perguntado onde pretendiam realizar o seu projeto de vida, a resposta obtida remete que $57 \%$ pretendem realizar os seus projetos de vida na cidade e $31 \%$ responderam no campo. Nesse mesmo sentido foi perguntado aos pais onde pretendiam que seus filhos realizassem seus projetos de vida, a resposta obtida sinaliza que 69\% dos mesmos seguem perspectiva parecida com a dos filhos, uma vez que apenas $31 \%$ dos pais projetam a continuação desses jovens no campo.

Isso demonstra uma tendência para o esvaziamento do campo que é motivo de preocupação, pois é visto que esse processo trará consequências para toda a sociedade.

Gráfico 3:

Onde pretendem realizar o seu projeto de vida

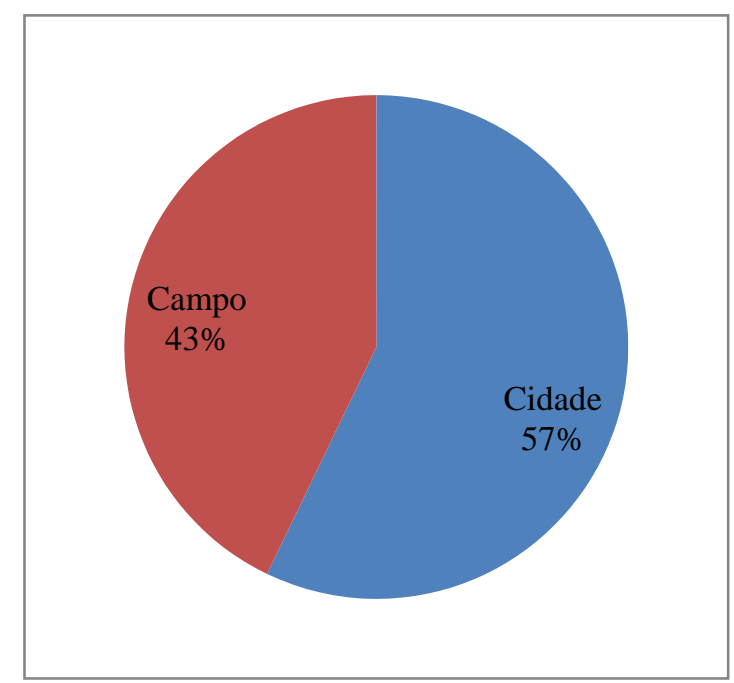

Fonte: Resultado, elaboração própria/2018
Gráfico 4:

Onde pretende que seus filhos realizem o seu projeto de vida

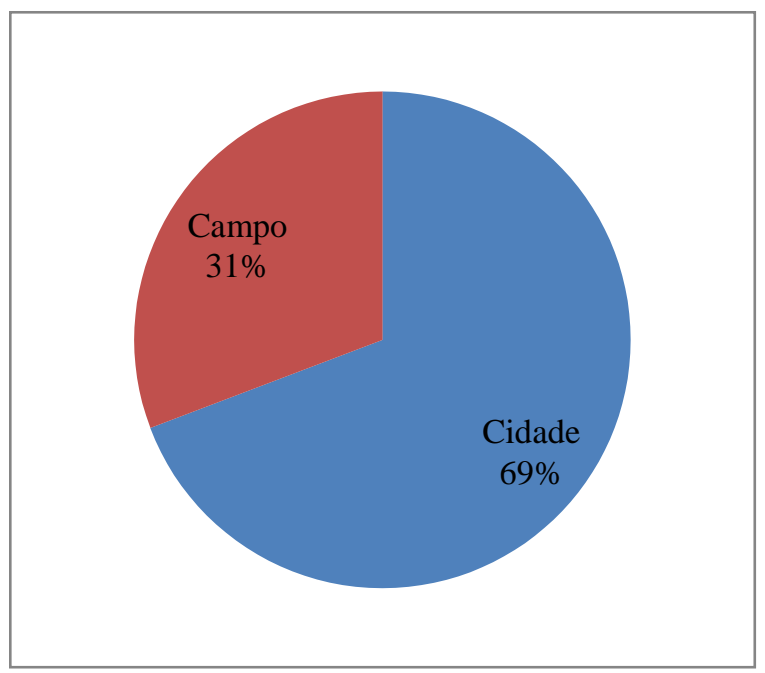

Fonte: Resultado, elaboração própria/2018.

Foi questionado aos jovens o que pretendem fazer quando concluir o ensino médio, $73 \%$ dos mesmos responderam que querem cursar uma faculdade, 14\% responderam que querem arrumar um emprego, $9 \%$ ainda não decidiu o que fazer e $4 \%$ responderam que gostariam de fazer outras atividades, sem especificá-las. Quando comparados aos gráficos 3 e 4 se percebe que a vontade dos jovens em abandonar as atividades agrícolas e buscar na cidade outras oportunidades é uma questão recorrente.

Gráfico 5: O que pretende fazer quando terminar o ensino médio 


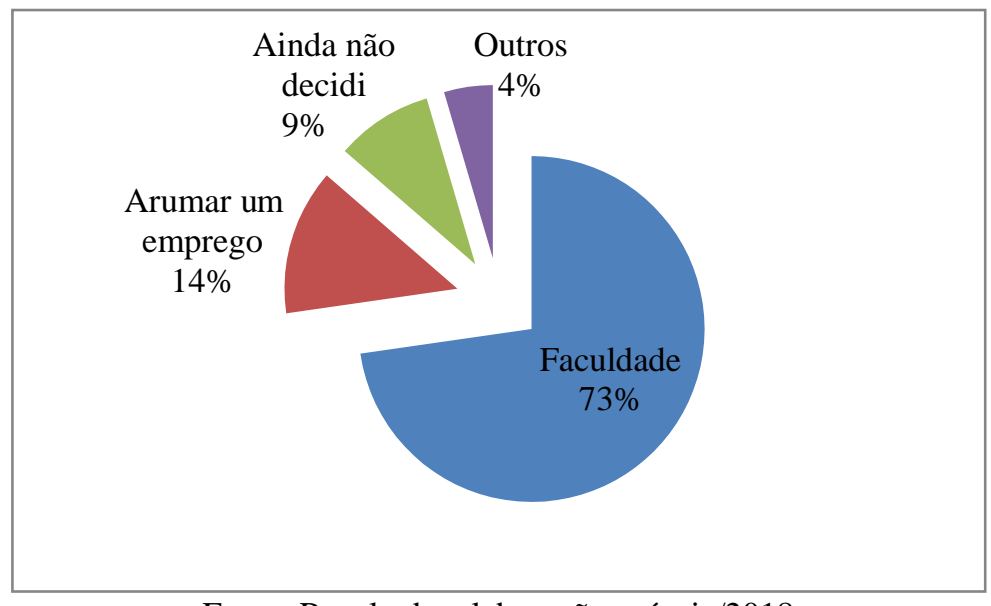

Fonte: Resultado, elaboração própria/2018.

Sobre o que os pais acham da realidade rural vivida pelos jovens de hoje, $85 \%$ dos mesmos consideram que a realidade rural vivida hoje das pessoas que residem no assentamento São Jose não contribui para manter os jovens no meio rural e somente $15 \%$ consideram que contribuem.

Gráfico 6: A realidade rural vivida hoje pelos jovens contribui para mantê-los no meio rural

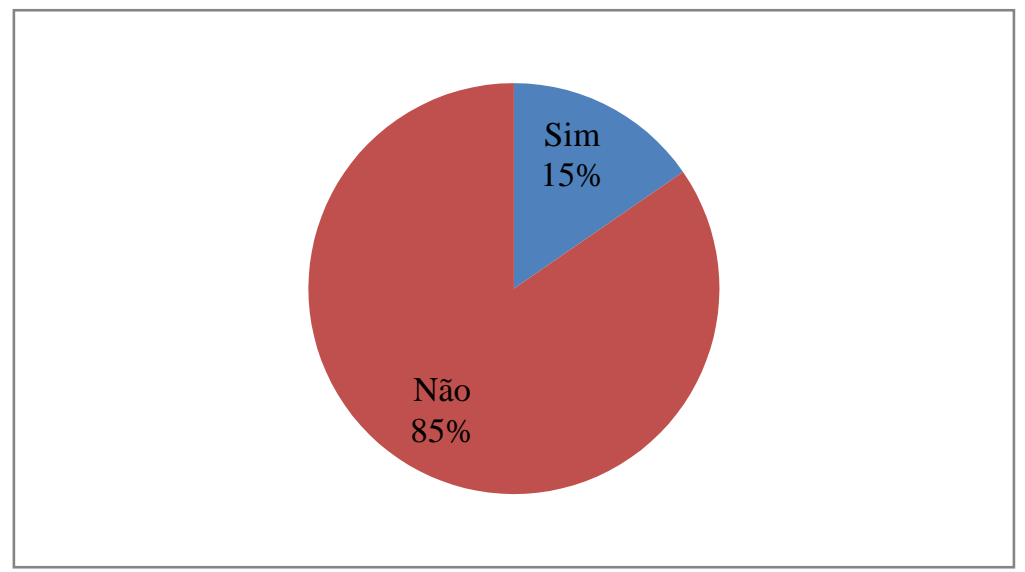

Fonte: Resultado, elaboração própria/2018.

Quanto ao incentivo da família para continuar no campo 38\% dos jovens responderam que são pouco incentivados, $33 \%$ são medianamente e $29 \%$ são muito incentivados. O que se pode perceber é a baixa influência dos pais para os filhos permanecerem na propriedade contribuindo para o êxodo rural.

Gráfico 7: Incentivo da família para continuar no campo 


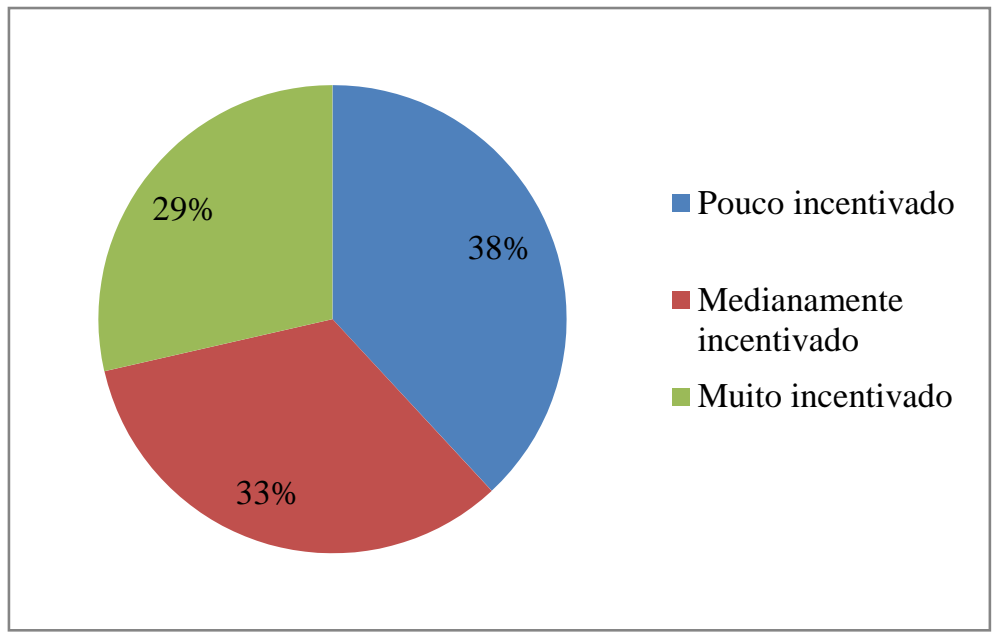

Fonte: Resultado, elaboração própria/2018.

Sobre a situação da propriedade exposta no gráfico 8 , percebe-se que $86 \%$ das propriedades em que vivem os jovens pesquisados são de posse de suas famílias, embora a maioria dessas propriedades se trate de áreas tuteladas pelo INCRA.

Gráfico 8: Situação das propriedades rurais

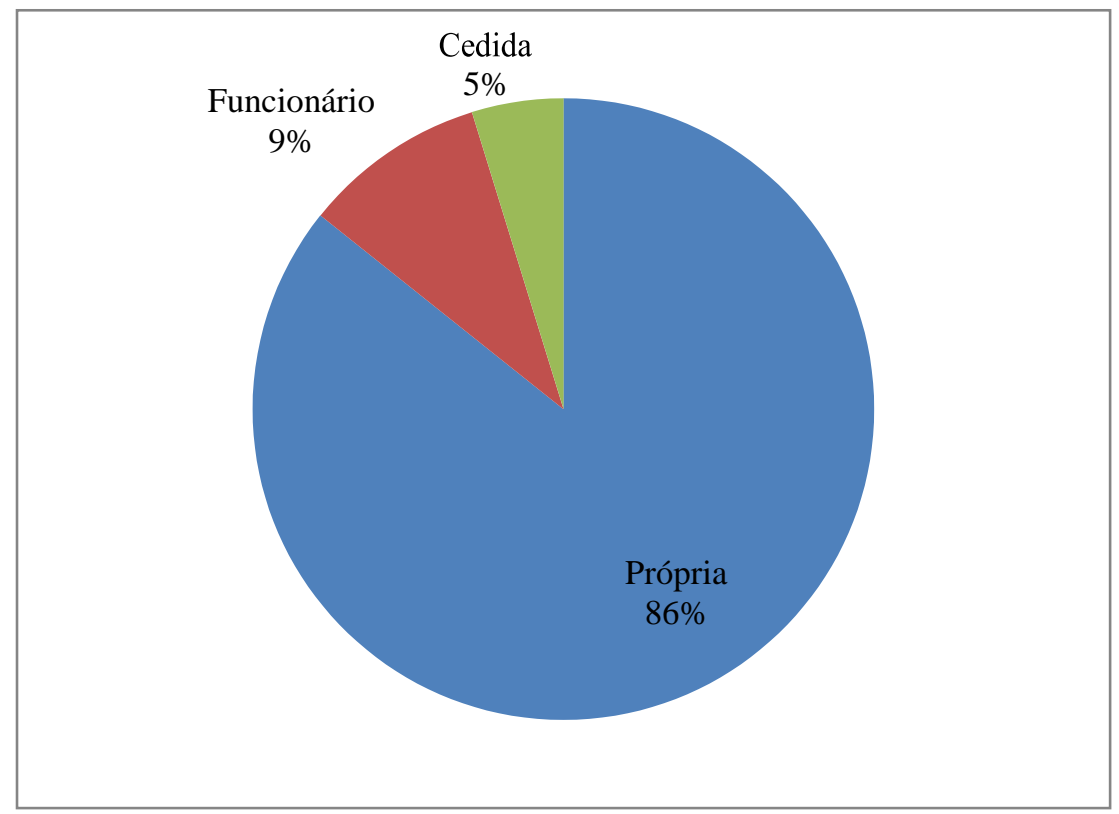

Fonte: Resultado, elaboração própria/2018.

Quando questionados se participam das atividades agrícolas, $81 \%$ dos jovens responderam que sim, ou seja, participam das atividades desenvolvidas nas propriedades e $19 \%$ responderam que não ajudam os familiares. Embora sejam jovens em idade escolar e, por isso, ocupam parte do seu dia frequentando a escola, o número de participantes nas atividades 
agrícolas chama atenção, pois demonstra os princípios de organização do trabalho na agricultura familiar, pois os filhos ajudam seus pais nas atividades do campo. Levando em consideração que o envolvimento dos jovens na propriedade pode ser um condicionante para a permanência dos mesmos no campo, porque cria vínculo com a terra e a experiência de como gerar renda, esse fator pode contribuir para sua permanência.

Gráfico 9: participam nas atividades agrícolas

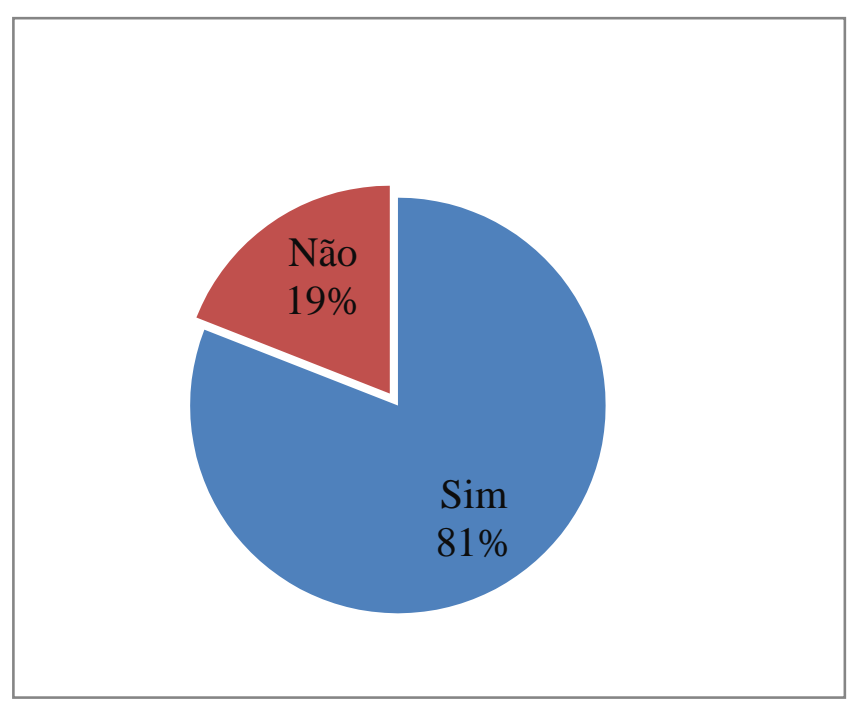

Fonte: Resultado, elaboração própria/2018.

A informação representada no gráfico 10 traz a discussão sobre o papel que a juventude do meio rural desempenha na continuação das atividades agrícolas desenvolvidas na propriedade em que moram, onde a saída desses jovens para a cidade resulta em uma desestabilização da agricultura familiar.

Gráfico 10: Mão de obra na propriedade rural

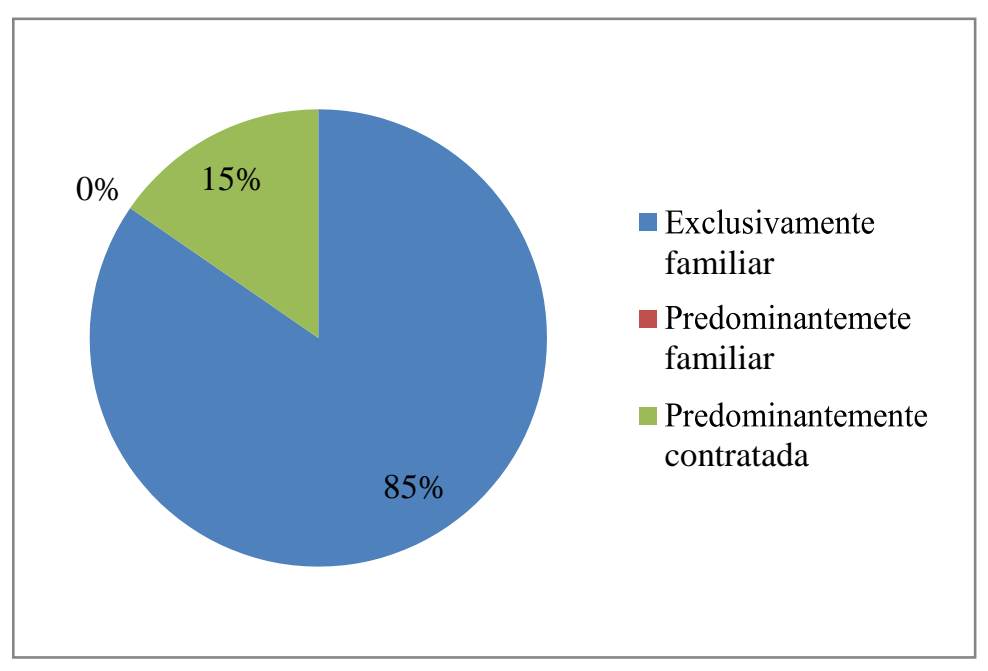


Fonte: Resultado, elaboração própria/2018.

O gráfico 11 mostra os principais problemas da vida do campo elencados pelos jovens, onde o trabalho "penoso" e a dificuldade de acesso ao ensino, sobretudo os cursos profissionalizantes e educação superior são os principais problemas vistos pelos jovens pesquisados. Os jovens consideram como trabalho penoso, o trabalho que exige esforço físico desgastante e a exposição aos fatores climáticos e ambientais que provocam uma sobrecarga ao organismo.

\section{Gráfico 11: Problemas da vida do campo}

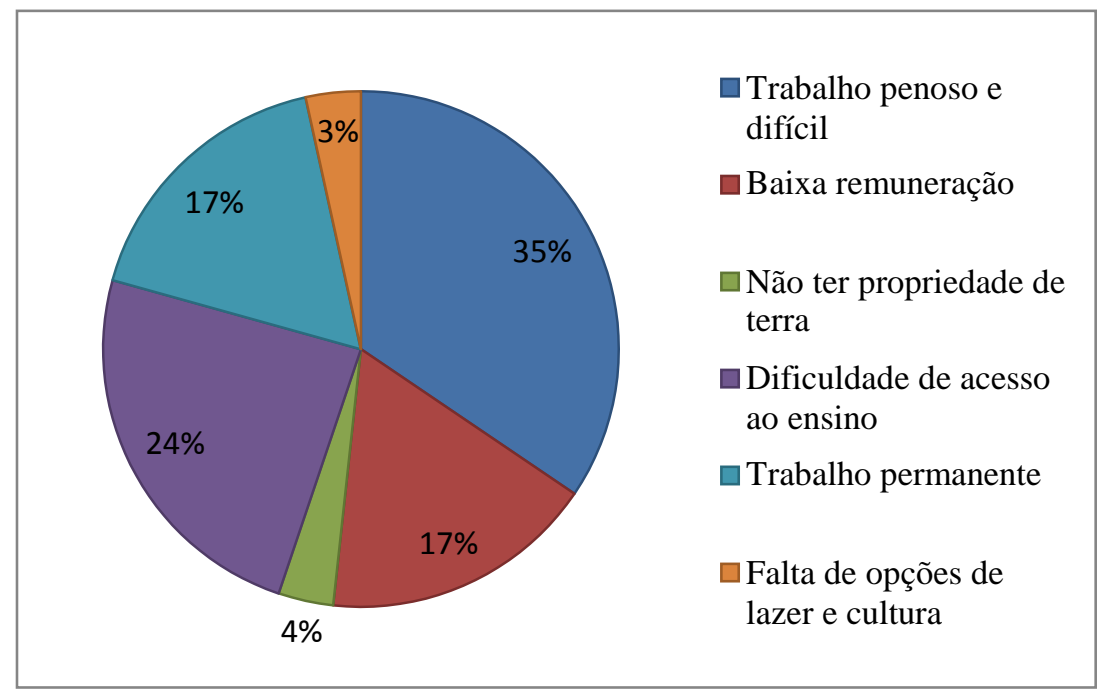

Fonte: Resultado, elaboração própria/2018.

Esses problemas provocam o anseio nos jovens de buscar os centros urbanos como alternativa diferente das que encontram no meio rural.

Quando perguntado, se vivendo no campo as suas necessidades enquanto jovens são atendidas, $33 \%$ dos alunos responderam que sim, no entanto $67 \%$ um percentual considerado elevado, responderam que não.

\section{Gráfico 12: A vida no campo lhe atende em as necessidades}

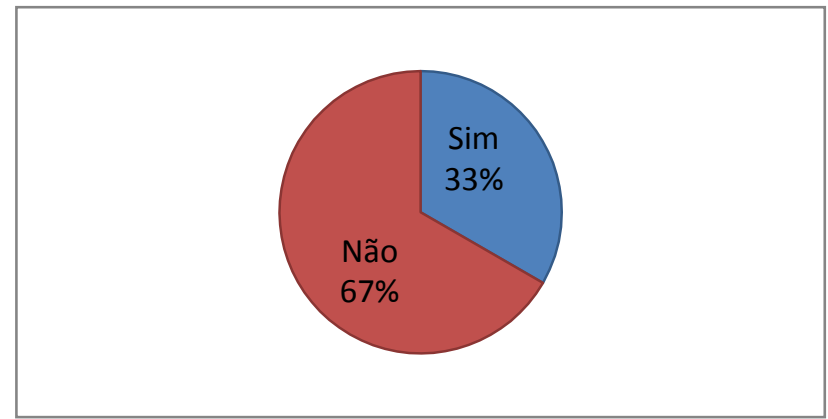

Fonte: Resultado, elaboração própria/2018. 
Muitos deles veem o campo como um lugar incapaz de atender as suas necessidades enquanto jovens, não somente sob a perspectiva da carreira profissional, mas no que se refere à inclusão social, lazer e cultura.

Quanto à motivação dos jovens de frequentar a escola, 76\% responderam que é em busca de um futuro melhor, seguidos de $14 \%$ que responderam que vão em busca de novos conhecimentos, com essa questão é possível observar a visão dos jovens quanto a importância de se passar pela escola.

Gráfico 13: Motivação de ir para escola

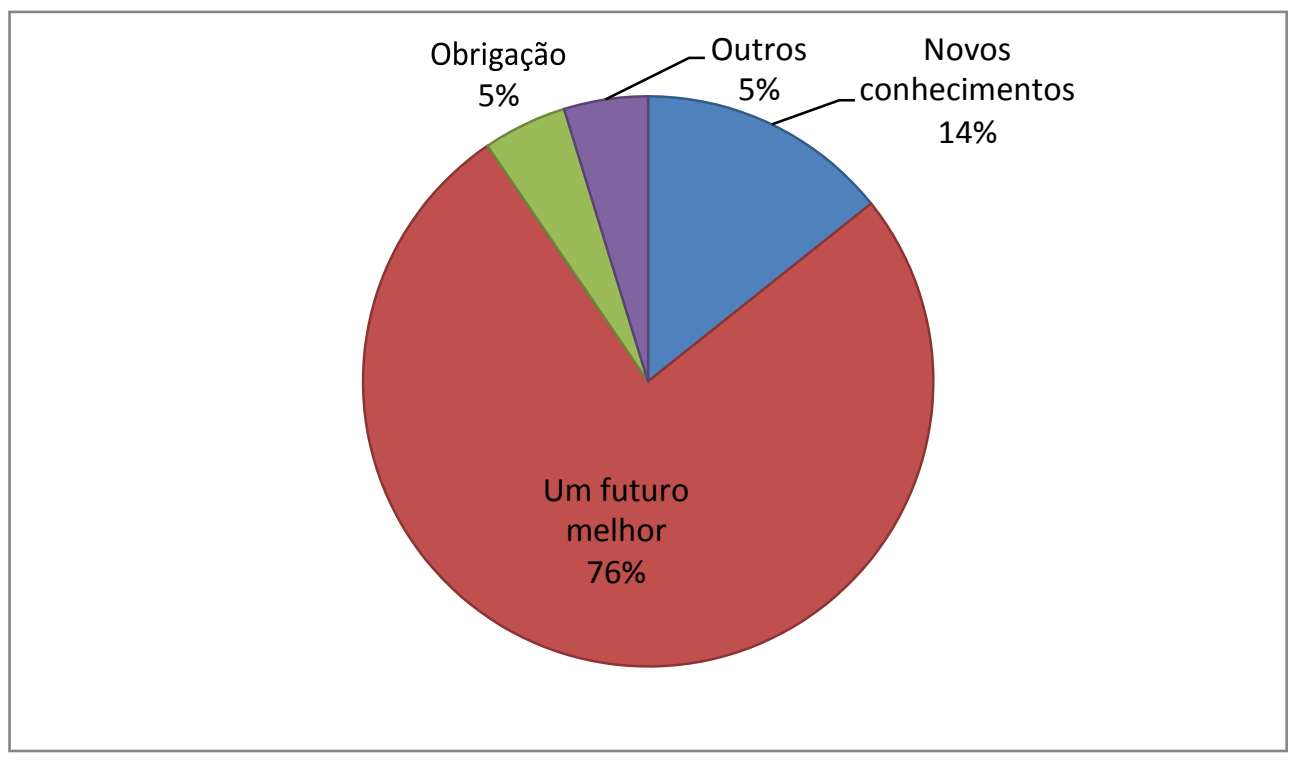

Fonte: Resultado, elaboração própria/2018.

Essa percepção remete-nos que o fator de motivação de frequentar a escola está relacionado a uma alternativa de melhoria nas condições de vida, seja permanecendo no campo ou tendo novas oportunidades na zona urbana. Visto que se o que querem para o futuro é diferente da realidade que vivenciam, veem a educação formal como o primeiro passo.

Ao ser perguntado aos pais se deveriam existir algo no meio rural para motivar os jovens a permanecerem no campo, dentre as respostas obtidas a maioria direciona para duas vertentes, as quais são: investimento do governo que correspondeu 54\% das respostas, e a melhoria na educação que representam 38\%, $8 \%$ dos entrevistados não souberam responder.

Gráfico 14: Ideias para que os jovens permaneçam no meio rural 


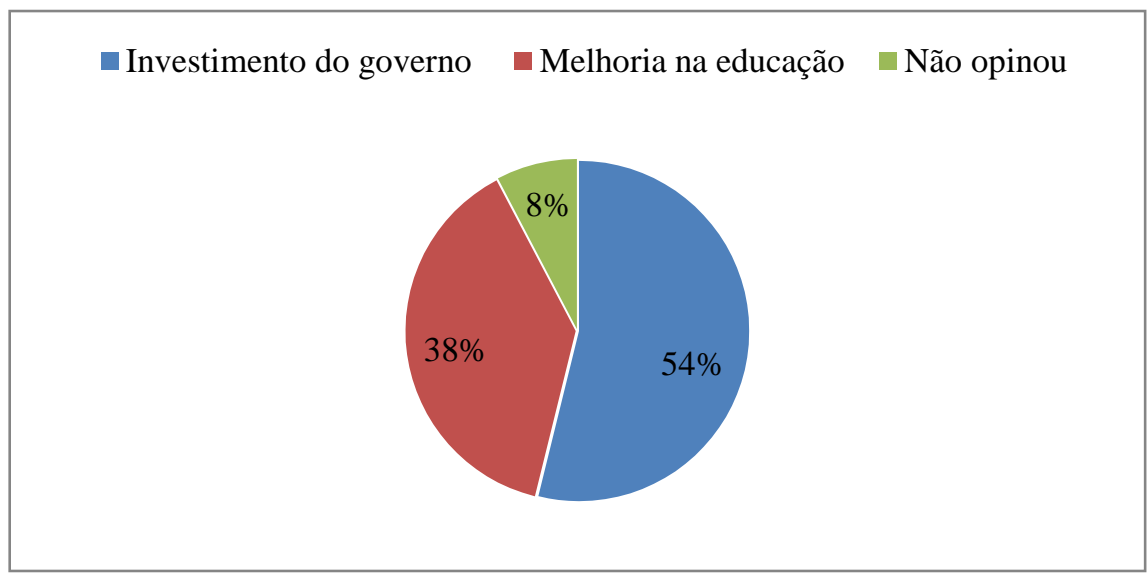

Fonte: Resultado, elaboração própria/2018.

As respostas dos pais nos leva a compreender as necessidades dos assentados a partir da concepção de Pages (2011, p.05) "políticas públicas que priorizem a educação para o campo, que valoriza a vida, a cultura, que estar no campo não é estar atrasado, é manter os laços, as tradições, os hábitos.”.

\section{Considerações finais}

Com esse estudo observando as variáveis que influenciam nas escolhas dos jovens em querer sair ou continuar o campo, identificou-se que a grande maioria dos jovens pretende sair do campo e buscar melhor qualidade de vida e novas condições como, estudo, oportunidades de emprego, lazer, entre outros.

Esses dados traz um alerta para as profundas transformações na comunidade rural, visto que a comunidade em estudo se caracteriza pelo desenvolvimento de uma agricultura familiar e o futuro dessas unidades produtivas depende do interesse dos jovens que são os futuros sucessores em permanecer ali. O que se apresenta é a falta de meios para incentivar, e gerar oportunidades do jovem se manter no campo.

Outro fato importante destacado é que os pais também não veem o campo como um lugar de oportunidade, de realização profissional e social para seus filhos, na pesquisa realizado deram ênfase muito mais nas dificuldades que a vida no campo proporciona, essa posição pode influenciar nas decisões do jovem.

É perceptível que possibilitar aos jovens que vivem no meio rural opções que envolvam lazer, oportunidades de estudo, e inserção no mundo do trabalho que permita obtenção de renda, 
já seria o suficiente para que a recorrência de evasão desses jovens do campo diminua. Vimos que as politicas públicas tem priorizados os arranjos produtivos ligados a agricultura mecanizada de grande escala em detrimento da agricultura familiar, por isso esta, não consegue desenvolver todo o seu potencial econômico.

Diante disto, observa-se que ao relacionar as perspectivas de futuro desses jovens com o meio em que vivem muitos deles enxergam-se distantes desse meio rural, dentre as variáveis e as motivações que influenciam nessa decisão dos jovens em permanecer ou sair do campo estão às condições de estudo, oportunidades de emprego, lazer, entre outros.

\section{Referências}

ABRAMOVAY, R. Agricultura familiar e serviço público: novos desafios para a extensão rural. Cadernos de Ciência \& Tecnologia, Brasília, v.15, n.1, p. 137-157, jan/abr.1998.

ARENHARDT, D., de Souza, M.; STEFANEL Franchi, T.: O jovem rural e seu olhar sobre o futuro: a busca por melhor condição de vida nos centros urbanos, em Contribuciones a las Ciências Sociales, Junio 2014. Disponível em: www.eumed.net/rev/cccss/28/juventuderural.html

BARROZO, J.C. Incertezas no Araguaia: a enxada enfrenta o trator. IN: JOANONI NETO, Vitale. (Org.). Política, ambiente e diversidade cultural: VI Seminário do ICHS/UFMT. Cuiabá: EdUFMT, 2007. P.49-61.

BARROZO, J.C.; ROSA, J.C. O Norte Araguaia mato-grossense como uma nova fronteira de expansão da soja Brasil (2000 a 2015). In: Diálogos Latino-americanos, 2017. p.172-188.

BREITENBACH Raquel; CORAZZA Graziela. Perspectiva de permanência no campo: Estudo dos jovens rurais de Alto Alegre, Rio Grande do Sul/Brasil. Revista ESPACIOS, Vol. 38 (No 29) ano 2017. Pág. 9

CARNEIRO, M. J. Herança e gênero entre agricultores familiares. Revista Estudos Feministas, Rio de Janeiro, No. 1, 22-55, 2001.

GODOY, C.M.T et al. Juventude rural, envelhecimento e o papel da aposentadoria no meio rural: A realidade do município de Santa Rosa/RS. In: $\mathbf{4 8}^{\circ}$ CONGRESSO da Sociedade Brasileira de Economia, Administração e Sociologia Rural, Campo Grande, 2010.

LIMA, Maria do Rosário Soares. A Transformação de Posseiros em Agricultores Familiares: História e Memoria da Reocupação de Vila Rica-MT. Dissertação (mestrado)Universidade Estadual de Mato Grosso, Instituto de Ciências Humanas e Sociais, Programa de Pós-Graduação em História, Cuiabá, 2016. 
PAGES, G.M. Educação do campo: problemas, desafios e perspectivas. 2011. Disponível em: https://www.webartigos.com/artigos/educacao-do-campo-problemas-desafios-eperspectivas/63665/

PUHL, J. I. O tempo do Grilo: Posseiros a Gleba São Domingos (1979-1983). Dissertação (Mestrado em História) - Universidade Federal de Mato Grosso. Cuiabá, 2003.

PUNTEL, J. A.; PAIVA, C. Á. N.; RAMOS, M. P. Situação e perspectivas dos jovens rurais no campo. Code, 2011. Disponível em:

http://ipea.gov.br/code2011/chamada2011/pdf/area3/area3-artigo20.pdf.

SCHNEIDER, S. A Pluriatividade na Agricultura Familiar. Porto Alegre, Editora da UFRGS. Segunda edição, (2003). 